\title{
Preventing carotid stroke
}

\author{
Kirk W. Beach \\ D. E. Strandness, Jr. Vascular Laboratory, Vascular Division, Department of Surgery and Department of Bioengineering, University of Washington, \\ Seattle, WA, USA \\ Correspondence to: Kirk W. Beach, PhD, MD, Emeritus Research Professor. D. E. Strandness, Jr. Vascular Laboratory, Vascular Division, Department \\ of Surgery and Department of Bioengineering, University of Washington, Seattle, WA 98195, USA. Email: kwbeach@usa.net.
}

Submitted Nov 23, 2021. Accepted for publication Dec 24, 2021.

doi: $10.21037 /$ atm-21-6296

View this article at: https://dx.doi.org/10.21037/atm-21-6296

Two special series focusing on issues regarding the prevention and treatment of stroke in people with carotid stenosis were published in this journal in 2020 and $2021(1,2)$. Among the articles: Del Brutto asks "Why are we still debating criteria for carotid artery stenosis?" (1); Lavenson advocates a "quick carotid (ultrasound) scan" to screen for carotid stenosis that might result in the prevention of more than 150,000 strokes each year saving more than $\$ 15,000,000,000$ in treatment and rehabilitation costs with an expenditure of nearly half that amount (2); Mechtouff explores the hemodynamics of the cerebroarterial circulation (2); Viticchi relates hypoperfusion to cognition (2). All of the articles describe in detail the empirical observations from large numbers of patients studied in attempts to discern which people have "significant" carotid stenosis $(1,2)$.

The continuing debate uses hemodynamic and other laboratory measures to predict properties of anatomic stenosis and then uses the properties of anatomic stenosis to predict stroke during subsequent life. Here, instead, I assert that extreme hemodynamic forces lead to chronic impaired cognition and to occasional catastrophic predictable stroke events: both can be prevented.

Nearly $10 \%$ of adults have a congenital disconnected circle of Willis (coW) leaving one internal carotid artery (ICA) as the sole supply of the ipsilateral middle cerebral artery (MCA) (3): 2\% supply both anterior cerebral arteries (ACA); 4\% supply the ipsilateral posterior cerebral artery (PCA). Although in $3.7 \%$ of cases, the isolated ICA supplies only the MCA with $3.3 \mathrm{cc} / \mathrm{s}$ in systole, in nearly $1 \%$ of cases, the isolated ICA in addition supplies both ACAs plus the ipsilateral PCA requiring a systolic ICA flow of $8.3 \mathrm{cc} / \mathrm{s}$ (Figure 1). After age 50 , nearly $10 \%$ of people develop a stenosis of the proximal ICA due to the growth of a medial monoclonal atheroma (4). When that atheroma thickens beyond $1.5 \mathrm{~mm}$ (5) vasa vasorum from the adventitia proliferate to invade the atheroma providing essential nutrition for the expanding atheroma. As the atheroma grows to embrace the lumen, compensatory adventitial dilation is arrested; further atheroma expansion impinges on the lumen causing stenosis. So long as the flow does not diminish, progressive reduction of stenotic diameter requires increased intrastenotic velocity (6). The Spencer/ Reid curve shows that when the stenosis becomes severe, in the absence of collateral flow via the coW, the high ICA resistance to flow results in regional cerebral hypotension (rCh). Spencer/Reid assume that the ICA supplies only the ipsilateral MCA and ACA. The hazardous stenoses are those that are the sole supply to the MCA and adjacent cerebral arteries (7). In that case, an intrastenotic velocity of $500 \mathrm{~cm} / \mathrm{s}$ creates a $100 \mathrm{mmHg}$ intrastenotic Venturi pressure depression promoting neovascular inflation and hemorrhage in the atheroma (8). With the onset of turbulence in the distal expansion of the stenosis marked by carotid bruit, the pressure difference across the stenosis can approach $100 \mathrm{mmHg}$ (modified Bernoulli equation) leaving dependent regions of the brain with critical $40 \mathrm{mmHg}$ hypotension in a patient with $140 \mathrm{mmHg}$ systemic systolic hypertension. This pressure difference across the stenosis can cause rupture of the atheroma releasing atheroembolic debris toward the hypotensive dependent brain regions. In addition to bruit, these cases have ophthalmic artery (OA) hypotension with ocular pulse delay; if untreated, $13.5 \%$ of these patients have stroke in 2 years (9). In addition to the MCA, the skin above the eyebrow (supraorbital angiosome $=\mathrm{SOA}$ ) is supplied by the ipsilateral ICA so when distal ICA pressure is low, the temperature of the SOA is more 
A

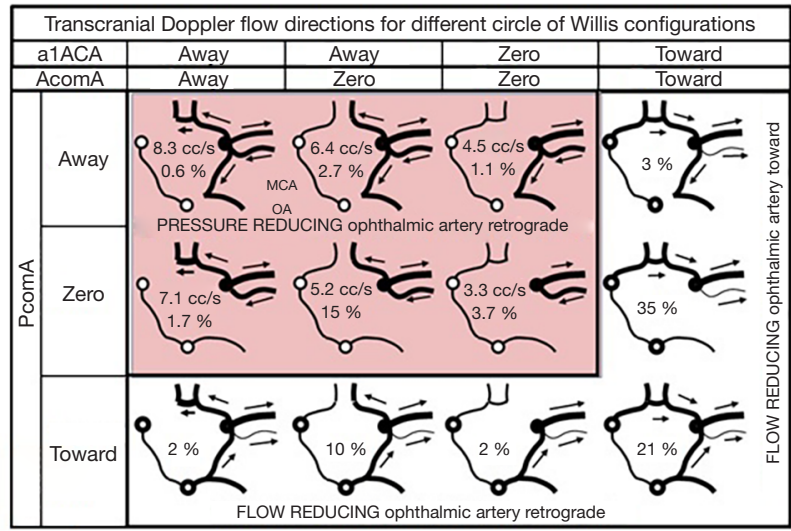

B

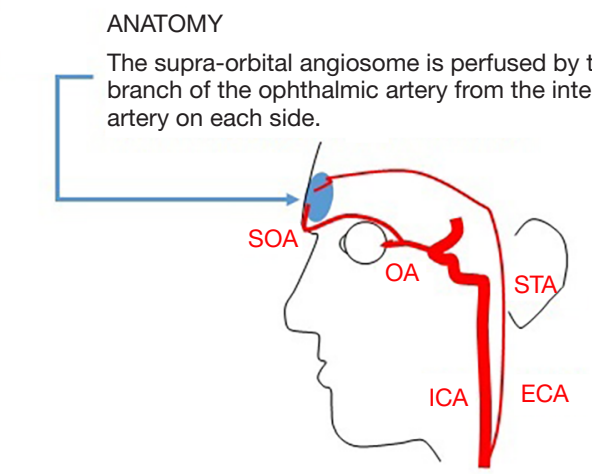

C

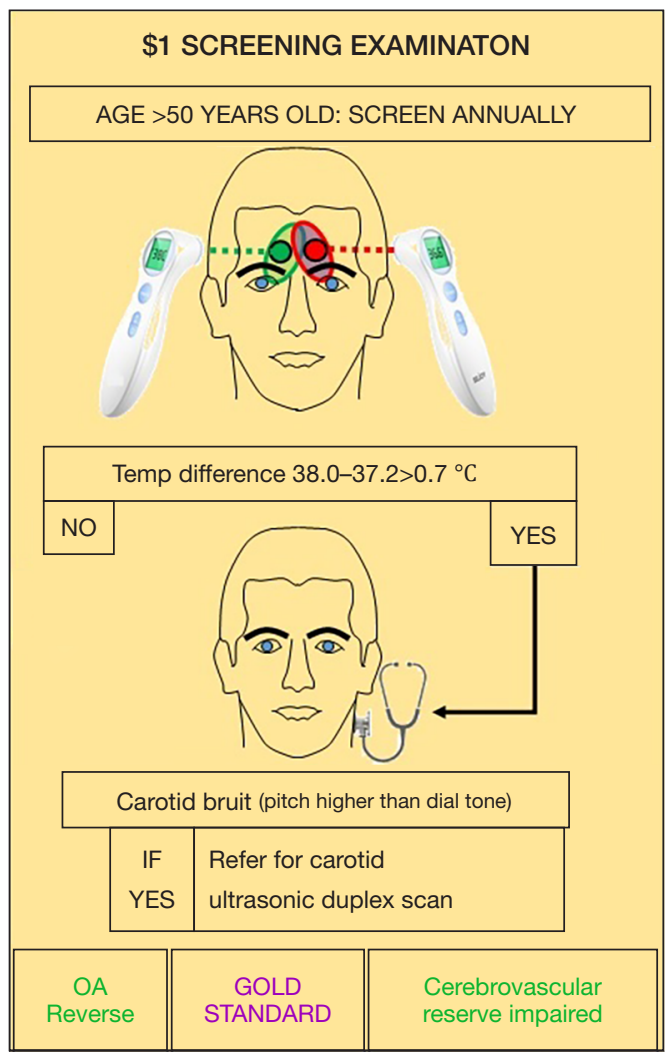

Figure 1 Essentials of a $\$ 1.00$ screening examination for pressure reducing carotid stenosis showing (A) congenital circle of Willis configurations (coW) with prevalence (\%) and flow (cc/s), (B) distribution of ICA flow to the SOA and (C) screening procedure. ACA, anterior cerebral arteries; SOA, supraorbital angiosome; OA, ophthalmic artery; STA, superficial temporal artery; ICA, internal carotid artery; ECA, external carotid artery.

than $0.7{ }^{\circ} \mathrm{C}$ below the contralateral normal skin, with a 99\% specificity for carotid stenosis (10). Patients with severe ICA stenosis combined with an isolated ICA have a $43.7 \%$ chance of stroke in 2 years on medical treatment, and a $12.3 \%$ chance of stroke in 2 years with anatomic revascularization (11) making the number needed to treat $(\mathrm{NNT}=3)$ to prevent one stroke.

A screening program (Figure 1) in primary care might identify people who can benefit from anatomic carotid revascularization by endarterectomy or stent (CEA/CAS). All people over age 50 screened at annual physical exam with a non-contact infrared thermometer with a left/ right SOA temperature difference greater than $0.7{ }^{\circ} \mathrm{C}$ are evaluated with neck auscultation for ipsilateral carotid bruit to identify the cases most likely to benefit from CEA/ CAS. Expect 1/100 positive tests $(1,000,000 / 100,000,000$ in the USA). Those cases are referred for advanced
Doppler ultrasound studies including: bilateral systolic arm BP measurement, bilateral ultrasound spectral Doppler velocimetry with waveforms of the carotid arteries, directional OA waveforms, and, if "temporal windows" are present, MCAs with measurement of acceleration time plus $30 \mathrm{~s}$ breath-hold cerebrovascular reserve assessment. At least $1 / 10$ cases will test positive for ICA peak systolic velocity $>300 \mathrm{~cm} / \mathrm{s}$, OA reversal, prolonged MCA acceleration time (tardus parvus) and impaired cerebrovascular reserve. These 100,000 cases are most likely to benefit from CEA/CAS. At estimated costs of $\$ 1$ for supraorbital thermography, $\$ 300$ for carotid ultrasound examination, $\$ 10,000$ for carotid endarterectomy, and $\$ 100,000$ for stroke treatment/ rehabilitation, the cost of preventing 30,000 strokes would be $\$ 1.5$ billion, saving of 1.5 billion compared to the $\$ 3$ billion to treat their recovery and manage their disability.

Such a system can be implemented by individual 
geriatric practices using equipment on hand, tabulating the number of referrals with positive and negative vascular exams. With a reported specificity of $99 \%$ (10), the false positive rate should be low. Before CEA/CAS, a trial of aggressive antiatherosclerotic medical therapy monitoring for decreasing bruit frequency and duration plus increasing SOA temperature followed by vascular exam measurements is recommended. Before and after treatment, cognition measures should improve creating immediate diagnostic confidence within each geriatric practice bypassing the need for prolonged/expensive formal multicenter clinical trials. Although the sensitivity of the screening program might be near 50\% (10), this limitation does not detract from the value of the program.

\section{Acknowledgments}

Funding: None.

\section{Footnote}

Provenance and Peer Review: This article was a standard submission to the journal. The article did not undergo external peer review.

Conflicts of Interest: The author has completed the ICMJE uniform disclosure form (available at https://atm. amegroups.com/article/view/10.21037/atm-21-6296/coif). KWB is retired and receives no support beyond pensions. As an Emeritus Research Professor of Surgery and Bioengineering, University of Washington, he has access to library resources.

Ethical Statement: The author is accountable for all aspects of the work in ensuring that questions related to the accuracy or integrity of any part of the work are appropriately investigated and resolved.

Open Access Statement: This is an Open Access article distributed in accordance with the Creative Commons Attribution-NonCommercial-NoDerivs 4.0 International License (CC BY-NC-ND 4.0), which permits the non- commercial replication and distribution of the article with the strict proviso that no changes or edits are made and the original work is properly cited (including links to both the formal publication through the relevant DOI and the license). See: https://creativecommons.org/licenses/by-nc-nd/4.0/.

\section{References}

1. Paraskevas KI. editor. Carotid Artery Stenosis and Stroke: Prevention and Treatment Part I. 2020. Available online: https://atm.amegroups.com/post/view/carotid-arterystenosis-and-stroke-prevention-and-treatment-part-i

2. Paraskevas KI. editor. Carotid Artery Stenosis and StrokePrevention and Treatment Part II. 2021. Available online: https://atm.amegroups.com/post/view/carotid-arterystenosis-and-stroke-prevention-and-treatment-part-ii

3. De Silva KR, Silva R, Amaratunga D, et al. Types of the cerebral arterial circle (circle of Willis) in a Sri Lankan population. BMC Neurol 2011;11:5.

4. Benditt EP. The origin of atherosclerosis. Sci Am 1977;236:74-85.

5. Xu C, Yuan C, Stutzman E, et al. Quest for the Vulnerable Atheroma: Carotid Stenosis and Diametric Strain-A Feasibility Study. Ultrasound Med Biol 2016;42:699-716.

6. Spencer MP, Reid JM. Quantitation of carotid stenosis with continuous-wave (C-W) Doppler ultrasound. Stroke 1979;10:326-30.

7. Lal BK, Beach KW, Sumner DS. Intracranial collateralization determines hemodynamic forces for carotid plaque disruption. J Vasc Surg 2011;54:1461-71.

8. Beach KW, Hatsukami T, Detmer PR, et al. Carotid artery intraplaque hemorrhage and stenotic velocity. Stroke 1993;24:314-9.

9. Kartchner MM, McRae LP. Noninvasive evaluation and management of the "asymptomatic" carotid bruit. Surgery 1977;82:840-7.

10. Capistrant TD, Gumnit RJ. Detecting carotid occlusive disease by thermography. Stroke 1973;4:57-64.

11. Henderson RD, Eliasziw M, Fox AJ, et al. Angiographically defined collateral circulation and risk of stroke in patients with severe carotid artery stenosis. North American Symptomatic Carotid Endarterectomy Trial (NASCET) Group. Stroke 2000;31:128-32.
Cite this article as: Beach KW. Preventing carotid stroke. Ann Transl Med 2022;10(3):158. doi: 10.21037/atm-21-6296 